\title{
Biosynthesis and Degradation of Carotenoids in Ornamental Crops with specific reference to Chrysanthemum
}

\author{
Ambreena Din ${ }^{1 *}$, Muneeb A. Wani, Sajid A. Malik, Shameen Iqbal , Imtiyaz T. Nazki, \\ Farheen Naqash, Misba Majeed, Sumaira Shafi
}

${ }^{1}$ Division of Floriculture and Landscape Architecture, Faculty of Horticulture, Sher-e-Kashmir University of Agricultural Sciences and Technology of Kashmir, J\&K, India.

*Corresponding author: E-mail: dinambreena@ gmail.com

\begin{abstract}
Carotenoids are lipophilic secondary metabolites derived from the isoprenoid pathway, accumulated in most plant organs and widely used as an antioxidant. Carotenoids synthesized in chloroplasts are essential for protecting tissues against photo-oxidative damage in the green tissues of higher plants. The importance of carotenoids for plant growth and development is evident since at least two major phytohormones, strigolactones and abscisic acid, are derived from carotenoid precursors. In flowers, carotenoids synthesized in the chromoplasts provide colour to the petals, ranging from yellow to red, in order to attract pollinators and determines the commercial value of ornamental plants. On analysis in chrysanthemum, $\beta, \quad \varepsilon$-carotenoids, lutein and its derivatives, reflecting the high expression levels of lycopene e-cyclase (LCYE) were found in yellow petals compared to the ratio of $\beta, \beta$-carotenoids to total carotenoids found in leaves reflecting the high expression levels of lycopene $\beta$-cyclase (LCYB). Petals of the yellowflowered cultivar Yellow Paragon showed increased accumulation and drastic componential changes of carotenoids as they mature, compared to petals of the white-flowered cultivar Paragon that showed drastically decreased carotenoid content during petal development.The white petals of chrysanthemum (Chrysanthemum morifolium Ramat.) contain a factor that inhibits the accumulation of carotenoids. All the white-flowered chrysanthemum cultivars tested showed high levels of $\mathrm{CmCCD} 4 \mathrm{a}$ transcript in their petals, whereas most of the yellow flowered cultivars showed extremely low levels indicating that in white petals of chrysanthemums, carotenoids are synthesized but subsequently degraded into colourless compounds, which results in the white colour. Studying the regulatory
\end{abstract}

mechanisms underlying carotenoid accumulation in ornamental plants at the molecular level will help in producing novel coloured cultivars by plant transformation.

Keywords - Ornamental crops, Chrysanthemum, Carotenoids, Biosynthesis, Degradation.

\section{INTRODUCTION}

\subsection{Pigments:}

Plant compounds that are perceived by humans to have colour are generally referred to as 'pigments'. Their varied structures and colours have long fascinated chemists and biologists, who have examined their chemical and physical properties, their mode of synthesis, and their physiological and ecological roles. Anthocyanins, a class of flavonoids derived ultimately from phenylalanine, are water-soluble, synthesized in the cytosol, and localized in vacuoles. They provide a wide range of colours ranging from orange/red to violet/blue. In addition to various modifications to their structures, their specific colour also depends on co-pigments, metal ions and $\mathrm{pH}$. They are widely distributed in the plant kingdom. The lipid-soluble, yellow-to-red carotenoids, a subclass of terpenoids, are also distributed ubiquitously in plants. They are synthesized in chloroplasts and are essential to the integrity of the photosynthetic apparatus. Betalains, also conferring yellow-to-red colours, are nitrogen-containing water-soluble compounds derived from tyrosine that are found only in a limited number of plant lineages. In contrast to anthocyanins and carotenoids, the biosynthetic pathway of betalains is only partially understood. All three classes of pigments act as visible signals to attract insects, birds and animals for pollination and seed dispersal. They also protect plants from damage caused by UV and visible light (Fig.1). 


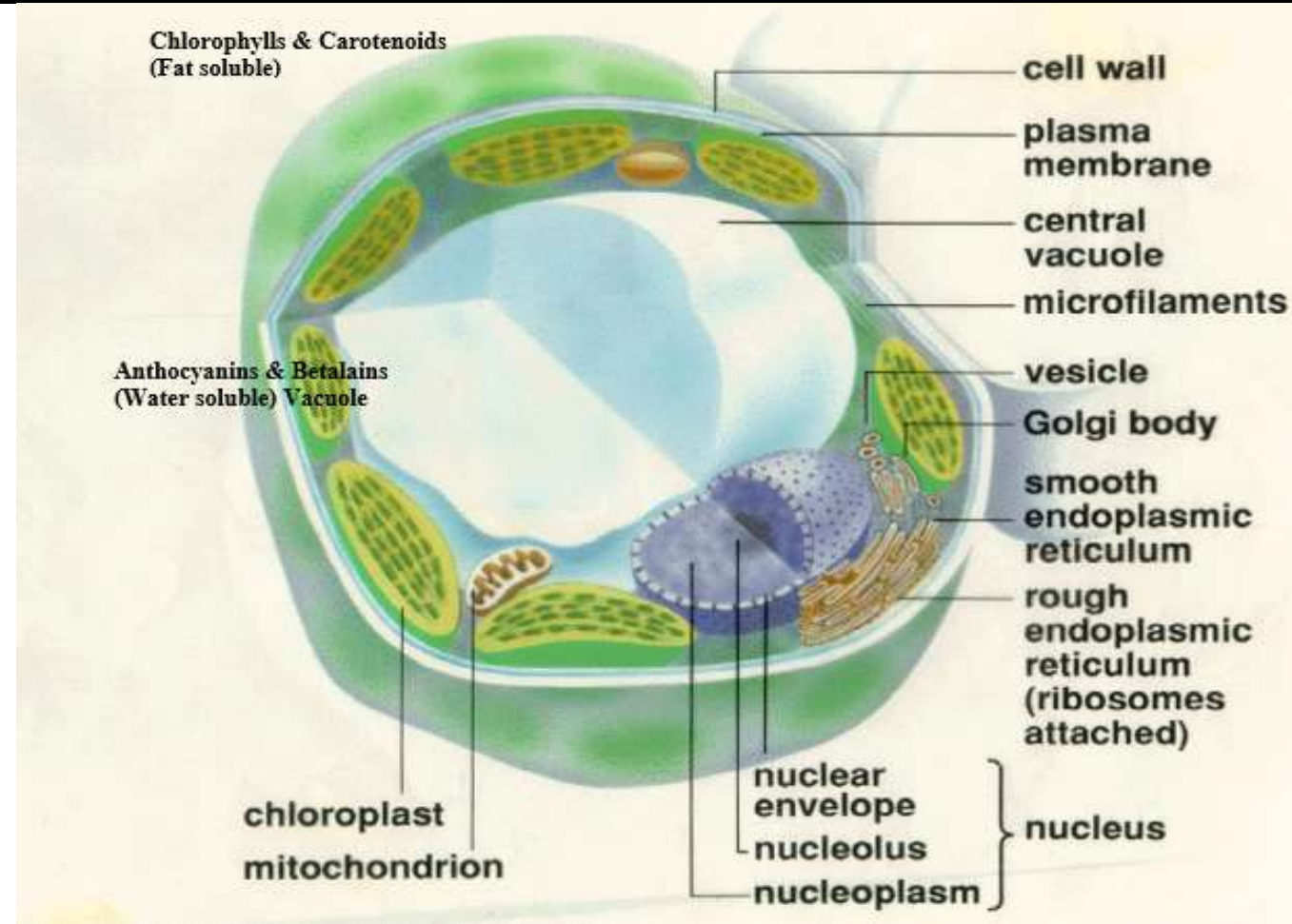

Generalized sketch of a plant cell.

Fig.1: Site of colour accumulation

\section{CAROTENOID BIOSYNTHESIS AND REGULATION IN PLANTS}

Carotenoids are lipophilic secondary metabolites derived from the isoprenoid pathway and are accumulated in most plant organs (Howitt \& Pogson, 2006). They contribute to the red, yellow and orange colours of many fruits and flowers, and are a factor in attracting pollinators to flowers. Carotenoids can exert important physiological functions in a wide range of organisms, including plants and humans. They are essential components of the photosynthetic machinery, and play a critical role in preventing photo oxidative damage (Howitt \& Pogson,2006). Carotenoid catabolism products, such as $\beta$ ionones, are involved in plant-insect interactions. The importance of carotenoids for plant growth and development is evident since at least two major phytohormones, strigolactones and abscisic acid, are derived from carotenoid precursors (Cazzonelli \& Pogson, 2010). Some carotenoids are precursors of vitamin-A, and prevent human age-related macular degeneration. Others, like lycopene, a red carotenoid pigment contained in tomato and watermelon, is a potent antioxidant and is considered to prevent prostate cancer. Astaxanthin, another red carotenoid, is found mainly in red sea animals and some algae, is likely to prevent cardiovascular disease and UV-light aging in the human body. Carotenoids are also widely used as colourants in the food and cosmetic industries, and some are important supplements in livestock and fish feed formulations.
Although carotenoid biosynthesis in plants has been well investigated, extensive studies on its regulation are relatively limited. Knowledge of carotenoid biosynthesis and regulation has led to a plethora of successful attempts at metabolic engineering of carotenoids in economically important crops (Giulianoet al. 2008). Here, we briefly summarize carotenoid biosynthesis, and identify steps that control the flux through the pathway. In addition to the rate of biosynthesis, sequestration and the storage capacity of the cell, along with the rate of carotenoid catabolism, all play a significant role in determining the levels of carotenoid accumulation in plant tissues and organs.

\subsection{Carotenoid biosynthesis}

Since the landmark review paper by Cunningham and Gantt (Cunningham \&Gantt, 1998), major discoveries have been made in the characterization of carotenoid biosynthesis and its regulation in plants. The core carotenoid pathway is conserved in most plant species although some plants accumulate special and rare carotenoids via unique biosynthetic routes (Fig.2). As isoprenoids, carotenoid compounds originate in the plastid-localized 2-C-methyl-D-erythritol 4-phosphate (MEP) pathway that starts with the reaction between pyruvate and glyceraldehyde-3-phosphate. The first steps in the MEP pathway are regulated by 1-deoxy-Dxylulose-5-phostaphate synthase (DXS) and 1-deoxy-Dxylulose 5-phosphate reductoisomerase (DXR) (Fig.2). The second key regulatory step is catalysed by 1-hydroxy2-methyl-2-(E)-butenyl 4-diphosphate reductase (HDR) 
eventually leading to the production of isopentenyl diphosphate (IPP) and dimethylallyl diphosphate (DMAPP) (Fig.2 ). Geranyl-geranyl diphosphate (GGPP) synthase catalyses the condensation of three molecules of IPP and one molecule of DMAPP to produce GGPP - a 20-carbon molecule. The first committed step in carotenoid biosynthesis is the condensation of two molecules of GGPP by phytoene synthase (PSY) to form phytoene (Fig.2). GGPP is also the precursor for several other groups of metabolites, including chlorophylls, ubiquinones and tocopherols. Phytoene then undergoes four sequential reactions to form lycopene.

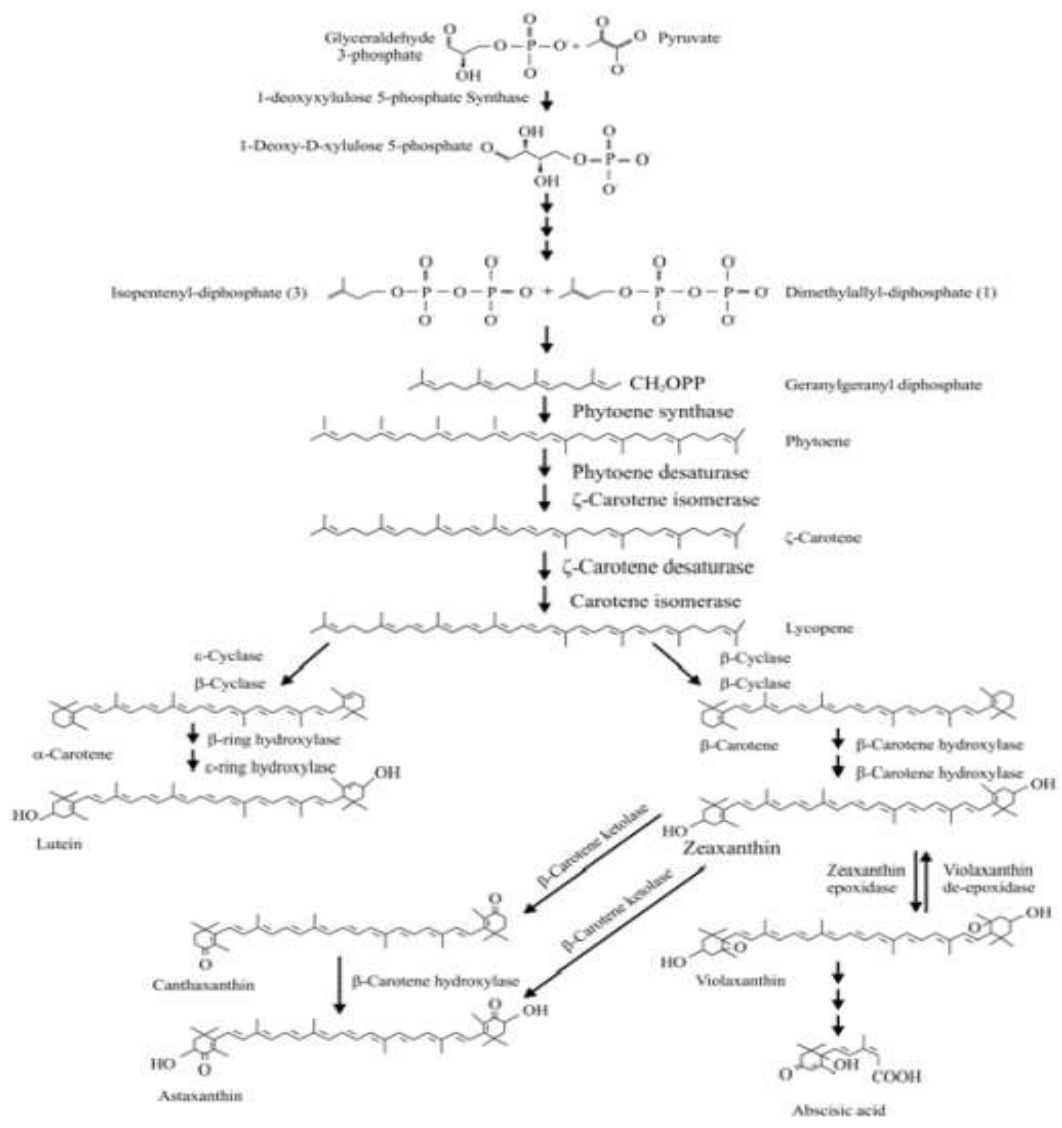

Fig.2: Carotenoid biosynthesis pathways

In bacteria, only one phytoene desaturase, crtI, catalyzes the conversion of phytoene to lycopene; however in plants, at least four enzymes are required for this step. These enzymes are phytoene desaturase (PDS) and zetacarotene desaturase (ZDS) which produce respective poly-cis-compounds, which are then isomerized to transforms by zeta carotene isomerase (ZISO) and carotenoid isomerase (CRTISO) to produce lycopene.In higher plants, the cyclization of lycopene with lycopene $\varepsilon$ and $\beta$-cyclases is a critical branch-point in carotenoid biosynthesis (Cazzonelli \& Pogson,2010,Fig.2). In one branch, a single enzyme, lycopene $\beta$-cyclase ( $\beta$-CYC), introduces a $\beta$-ring at both ends of lycopene to form $\beta$ carotene in a sequential two-step reaction. The first dedicated reaction in the other branch, leading to lutein, requires both $\varepsilon$-CYC and lycopene $\beta$-cyclase $(\beta-\mathrm{CYC})$ to introduce one $\beta$ - and one $\varepsilon$-ring into lycopene to form $\alpha$ carotene. $\alpha$-Carotene is acted upon by a $\beta$-ring hydroxylase to form zeinoxanthin, which is then hydroxylated by an $\varepsilon$-ring hydroxylase to produce lutein. Unlike plants, the cyanobacterium Prochlorococcus- marinus MED4 encodes a $\varepsilon-C Y C$ that can simultaneously catalyze the formation of $\alpha-, \beta$ - and $\varepsilon$-carotenes. Carotenoids with two $\varepsilon$-rings are rare in plants and algae, with an exception in lettuce, wherein a single $\varepsilon$-CYC adds two $\varepsilon$-rings to lycopene to form lactucaxanthin (Cunningham \& Gantt, 2001). $\beta$-Carotene can be hydroxylated in a two-step reaction to zeaxanthin, with $\beta$ cryptoxanthin as an intermediate product. In green tissues, zeaxanthin can be epoxidized to violaxanthiun, and a set of light- and dark-controlled reactions known as the xanthophyll cycle rapidly optimize the concentration of violaxanthin and zeaxanthin in the cell through the action of zeaxanthin epoxidase and violaxanthin de-epoxidase, respectively, via antheraxanthin (Demmig \& Adams,2002).

\subsubsection{Regulation of carotenoid biosynthesis}

Carotenoid accumulation occurs in most plant tissues, including green shoots, flowers, fruits, seeds and roots. Although the contents and types of carotenoids of green tissues are relatively conserved across most plant species, 
the levels of carotenoids and their profiles in non-green tissues, such as flowers, fruits and seeds, vary considerably, and are influenced by many factors, including the developmental stage, environment, stress or a combination of these (Howitt \& Pogson ,2006). In general, the steady-state levels of carotenoids are determined by the rate of biosynthesis, storage capacity of the cell and the rate of catabolism and degradation. Combined, these factors have made the study of carotenoid regulation challenging. Here, we discuss the important steps that has been used in the metabolic engineering of carotenoid biosynthesis in plants.

\subsubsection{Isopentenyl pyrophosphate (IPP) biosynthesis}

The fact that the first reaction in the MEP pathway is catalyzed by the DXS enzyme makes it a presumptive regulatory step in carotenoid biosynthesis. The initial evidence in support of this came from results of overexpressing and silencing of the DXS gene in Arabidopsis seedlings. Overexpression of DXS was shown to result in up to $112-131 \%$ increase in the total carotenoid content, whereas silencing of this gene reduced the carotenoid content by $75-87 \%$ relative to the wild type control. $D X S$ has been exploited in biotechnological applications to improve the carotenoid content of crops.

\subsubsection{Phytoene biosynthesis}

Phytoene biosynthesis is the first committed step in carotenoid biosynthesis, and has long been considered a 'bottleneck' in the pathway. Except for Arabidopsis, most other plant species express multiple functionally redundant copies of phytoene synthase (PSY), although different $P S Y$ genes appear to be differentially expressed and regulated. In Arabidopsis, its single copy PSY gene is tightly regulated by light. A phytochrome-interacting transcription factor, RIF, binds to the PSYpromoter and maintains it in a repressed state under dark conditions. Under light conditions, RIF degrades and dissociates from the $P S Y$ promoter, thus allowing for its active expression (Toledo \& Rodríguez, 2010). Another transcription factor, RAP2.2, was also shown to bind to the $P S Y$ promoter and regulate $P S Y$ expression and carotenoid levels.

\subsubsection{Lycopene biosynthesis}

The first step in lycopene biosynthesis is catalyzed by phytoene desaturase (PDS). The promoter of the Arabidopsis $P D S$ gene was found to have a regulatory region similar to that of the binding site of the RAP2.2 transcription factor to the $P S Y$ promoter, and analysis showed that RAP2.2 does indeed bind to the PDS promoter and affect carotenoid accumulation. Carotenoid isomerization catalyzed by CRTISO, which isomerizes cis bonds to all-trans lycopene, is another step with regulatory impact on carotenoid biosynthesis.
Characterization of the ccrl locus of Arabidopsis revealed that it encodes a histone methyl-transferase (SET DOMAIN GROUP, SDG8). This enzyme catalyzes the methylation of chromatin histones, and when the expression of $S D G 8$ gene was disrupted, it caused a reduction in the levels of CRTISO transcript and carotenoid content (Cazzonelli et al. 2010). In addition, Arabidopsis plants with reduced SDG8expression showed altered shoot and root branching, which were possibly caused by changes in levels of branch-inhibiting strigolocatone hormones that are derived from carotenoid catabolism products (Cazzonelli \& Pogson, 2010). This was the first report on epigenetic regulation of carotenoid biosynthesis; this breakthrough has the potential to open new avenues for engineering of carotenoids in plants.

\subsubsection{Lycopene cyclization}

The carotenoid biosynthesis pathway branches after the formation of lycopene. One branch forms carotenoids with two $\beta$-rings, while the other introduces both $\beta$ - and $\varepsilon$ rings to lycopene to form $\alpha$-carotene, which is then converted to lutein. Thus, the relative activities of $\beta$-CYC and $\varepsilon$-CYC would be expected to determine the proportion of lycopene channeled to the two branches of the carotenoid pathway; i.e. $\beta, \beta$ - and $\varepsilon, \beta$-carotenoids . Flux through the carotenoid pathway may play a role in controlling $\varepsilon$-CYC.

\subsubsection{Sequestration and storage}

In addition to the rate of carotenoid biosynthesis, other factors, such as sequestration and availability of storage compartments, play a significant role in determining levels of carotenoid accumulation. Even though carotenoid biosynthetic enzymes are nuclear-encoded, they are all located in the plastids, where carotenoids are synthesized and accumulated. In chloroplasts, most carotenoids accumulate in the form of chlorophyllcarotenoid-protein complexes in the thylakoid membranes associated with light-harvesting antenna. These complexes play an important role in stabilizing plant light-harvesting complexes (LHCs) and in assembling a functional photosystem II (PSII). Seed carotenoids are compartmentalized to elaioplasts (lipidstoring plastids), which use specialized lipoproteinsequestering structures to store large quantities of carotenoids (Howitt \& Pogson 2006). In chromoplasts, significant amounts of carotenoids may be stored in membranes, oil bodies or other crystalline structures within the stroma (Howitt \& Pogson 2006, Cunningham \& Gantt 1998).Reports in the literature have shown cases where enhanced carotenoid accumulation was accompanied by changes in the anatomical structure of plastids, resulting in enhanced ability to store carotenoids (Paolillo et al. 2004). Further analysis revealed changes in 
the thylakoid membranes of the plastids, thus allowing them to store large quantities of carotenoids (Paolilloet al. 2004). The authors therefore suggested that enhanced carotenoid accumulation could be due to changes in the cell structure, thus allowing for storage of more carotenoids.

\subsubsection{Catabolism and degradation}

A study revealed that carotenoids are constantly synthesized and degraded (Beisel, K.G.et al. 2010).This presumably maintains carotenoids at physiological levels, especially in green tissues, where a constant ratio of chlorophylls to carotenoids has to be maintained to ensure the integrity of the photosynthesis system. Carotenoid degradation by enzymatic oxidative cleavage produces an array of terpenoid products collectively known as apocarotenoids. These include abscisic acid and strigolactones, and other volatile and non-volatile compounds, which are well known in respective industries for their use as aromas, flavours and fragrances. Some apocarotenoids, e.g. $\beta$-ionone, are also known to play a role in plant-insect interactions.In Arabidopsis, the gene family that encodes carotenoid cleavage enzymes is comprised of at least nine members. Four of these encode carotenoid cleavage dioxygenases (CCD), and the remaining five encode 9-cis-expoxycarotenoid dioxygenases (NCED), with many of these enzymes exhibiting substrate promiscuity in vitro (Vogel, J.T. et al. 2010). The functions of some of these enzymes have been reported to be associated with certain apocarotenoids in several plant species. For example, CCD7 and CCD8 act in a coordinated manner in strigolactone biosynthesis, CCD1 is involved in $\beta$-ionone biosynthesis, and NCED2, NCED3, NCED5, NCED6 and NCED9 are associated with abscisic acid production (Walter \& Strack, 2011). In chrysanthemums, CCD activity is important for petal colour, and elevated transcript levels of CmCCD4a is reported to play a role in the degradation of yellow carotenoid pigments, which resulted in flowers with white petals.

\section{CAROTENOID BIOSYNTHESIS IN ORNAMENTAL CROPS}

Carotenoids are synthesized in chloroplasts and are essential for protecting tissues against photo-oxidative damage in the green tissues of higher plants (Britton, 1998). In flowers, carotenoids synthesized in the chromoplasts provide colour to the petals, ranging from yellow to red, in order to attract pollinators (Grotewold, 2006 and Tanaka et al. 2008). The colour of a flower is an important character that determines the commercial value of ornamental plants.
3.1. Carotenoid composition and carotenogenic gene expression during Ipomoea petal development.

Japanese morning glory (Ipomoea nil) is a representative plant lacking a yellow-flowered cultivar, although a few wild Ipomoea species contain carotenoids in their petals such as Ipomoea sp. (yellow petals) and I. obscura (paleyellow petals). In the present study, carotenoid composition and the expression patterns of carotenogenic genes during petal development were compared among I. nil, I. obscura, and Ipomoea sp. to identify the factors regulating carotenoid accumulation in Ipomoea plant petals. In the early stage, the carotenoid composition in petals of all the Ipomoea plants tested was the same as in the leaves mainly showing lutein, violaxanthin, and $\beta$ carotene (chloroplast-type carotenoids). However, in fully opened flowers, chloroplast-type carotenoids were entirely absent in I. nil, whereas they were present in trace amounts in the free form in I. obscura. At the late stage of petal development in Ipomoea sp., the majority of carotenoids were $\beta$-cryptoxanthin, zeaxanthin, and $\beta$ carotene (chromoplast-type carotenoids). In addition, most of them were present in the esterified form. Carotenogenic gene expression was notably lower in I. nil than in Ipomoea sp. In particular, $\beta$-ring hydroxylase (CHYB) was considerably suppressed in petals of both I. nil and I. obscura. The CHYB expression was found to be significantly high in the petals of Ipomoea sp. during the synthesis of chromoplast-type carotenoids. The expression levels of carotenoid cleavage genes (CCD1 and CCD4) were not correlated with the amount of carotenoids in petals. These results suggest that both I. obscura and I. nil lack the ability to synthesize chromoplast-type carotenoids because of the transcriptional down-regulation of carotenogenic genes. CHY B, an enzyme that catalyses the addition of a hydroxyl residue required for esterification, was found to be a key enzyme for the accumulation of chromoplasttype carotenoids in petals were analysed by HPLC. V, violaxanthin; N, neoxanthin; L, lutein; Z, zeaxanthin; A, antheraxanthin.

\subsubsection{Changes in carotenoid composition during petal development in Ipomoea.}

HPLC chromatograms of the carotenoid extracts obtained from the leaves of Ipomoea sp., I. obscura, and I. nil were similar. A representative chromatogram of Ipomoea sp. is shown in (Fig. 3A). The majority of the carotenoids in leaves were lutein, violaxanthin, and $\beta$-carotene, which are essential for photosynthesis. Carotenoids in the nonsaponified extract from leaves exhibited an HPLC chromatogram similar to those in the saponified leaf extract, except that chlorophyll $a$ and chlorophyll $b$ were detected in the non-saponified extract (Fig. 3B). The carotenoid composition in leaves was designated 
'chloroplast-type carotenoid'. The total carotenoid content in the leaves of all tested cultivars was around $300 \mu \mathrm{g} \mathrm{g}$ FW. Changes in the HPLC chromatograms of carotenoid extracts during petal development in Ipomoea plants are shown in (Fig. 4B and C). At stage 1, all petals tested were pale green and showed the same chromatograms as chloroplast-type carotenoids, mainly showing lutein, violaxanthin, and $\beta$-carotene, albeit at lower levels than in leaves $(<10 \mu \mathrm{g} \mathrm{g} \mathrm{FW})$. In petals of $I$. nil at stage 4 , the carotenoid content decreased below the detection limit, whereas small amounts of chloroplast-type carotenoids remained in I. obscura, and the carotenoids existed in the free form just as in leaves. In petals of Ipomoea sp. at stage 4, the carotenoid composition (designated 'chromoplast-type carotenoid') was completely different from the chloroplast-type carotenoids: lutein and violaxanthin levels were drastically reduced, and approximately $85 \%$ of the total carotenoids were made up of $\beta$-cryptoxanthin, zeaxanthin, and $\beta$-carotene. In addition, xanthophylls such as $\beta$-cryptoxanthin and zeaxanthin existed in the esterified form (Fig. 4C).

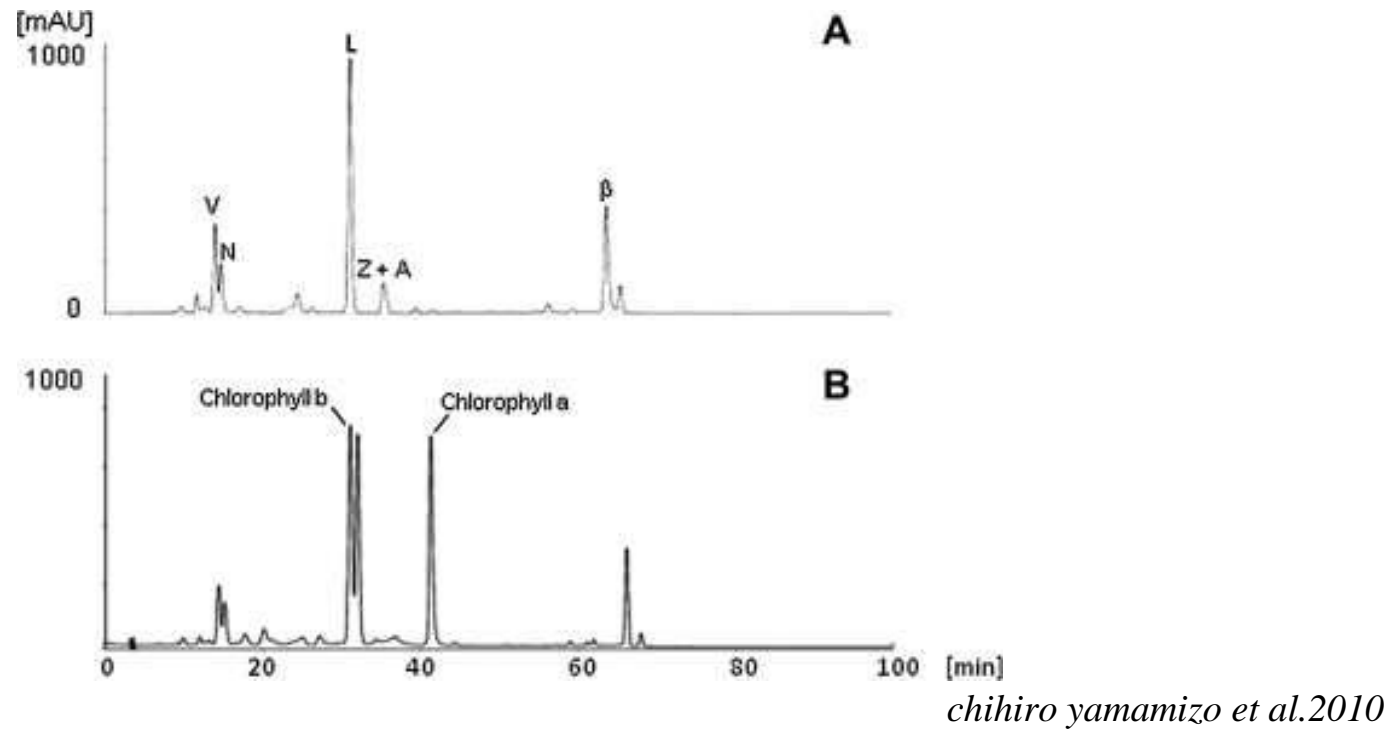

Fig.3: Carotenoid analysis in leaves of Ipomoea plants. Saponified (A) and nonsaponified (B) carotenoids extracted from 0.1 $g$ fresh weight $(F W)$ of leaves of Ipomoea sp.

A
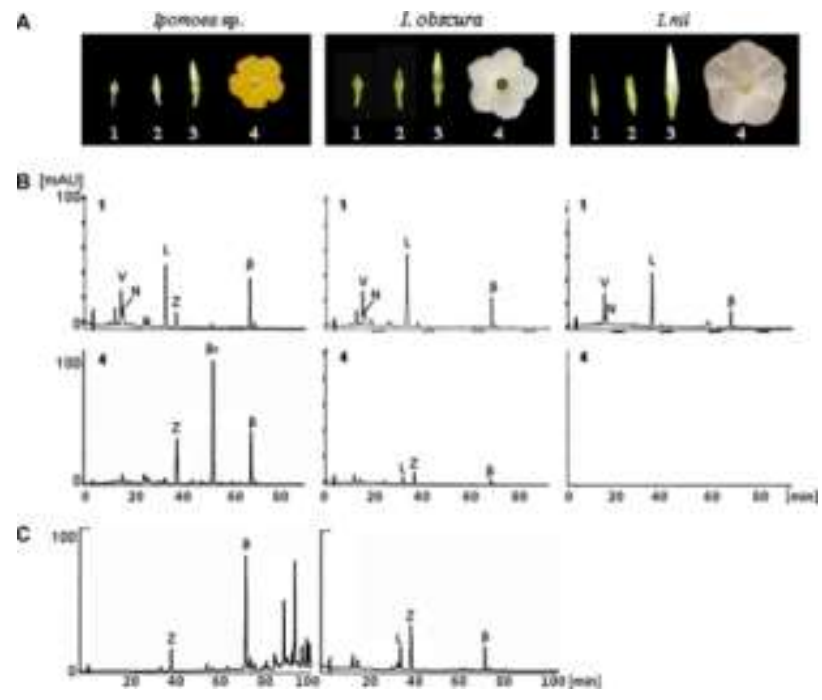

Chihiro yamamizo et al.2010

Fig. 4: Changes in carotenoid composition during petal development in Ipomoea plants. (A) Photographs of flowers at stages 1 and 4. HPLC elution profiles of saponified $(B)$ and non-saponified $(C)$ carotenoids extracted from petals of each species at various stages.

3.2. Carotenoid components in petals of yellow flower camellia species
Carotenoid components of eight yellow flower Camellia species were analyzed by HPLC (Fig.5). Carotenoid contents of these flower petals ranged from 0.8 to $11.3 \mu \mathrm{g}$ 
lutein equivalent $\cdot \mathrm{g}^{-1}$ Fresh Weight $(\mathrm{FW})$.Violaxanthin, (9Z)-violaxanthin, luteoxanthin, antheraxanthin, $\beta$ cryptoxanthin, and $\beta$-carotene were identified as carotenoid components and these compositions were similar among all of the examined yellow flower Camellia species. These carotenoids were accumulated as esterified forms in the petals (Natsu Tanikawa et al. 2010).

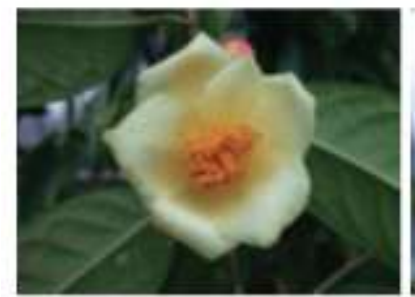

(a)

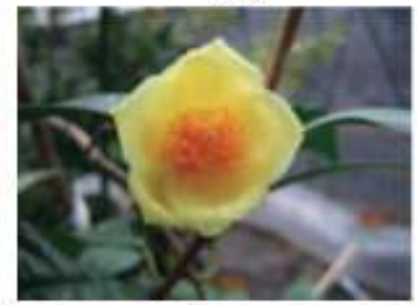

(c)

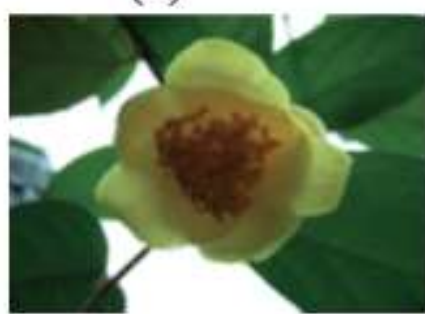

(e)

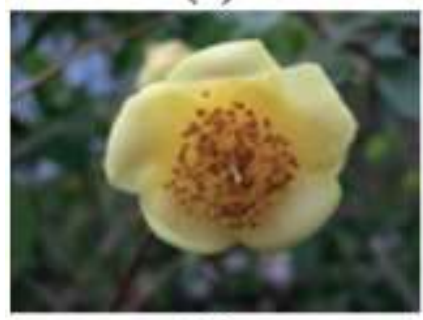

(g)

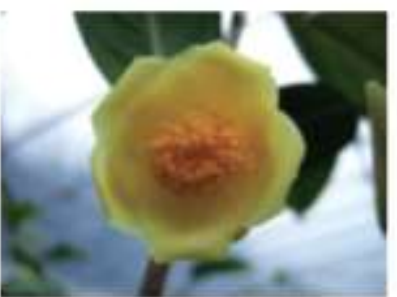

(b)

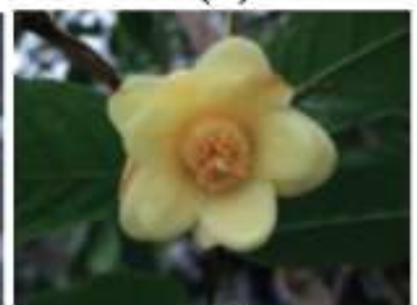

(d)

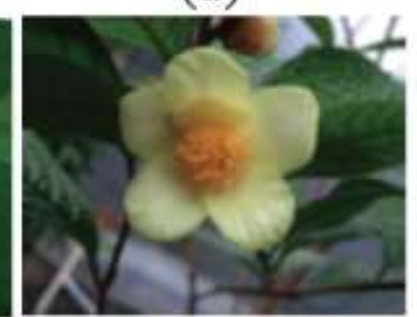

(f)

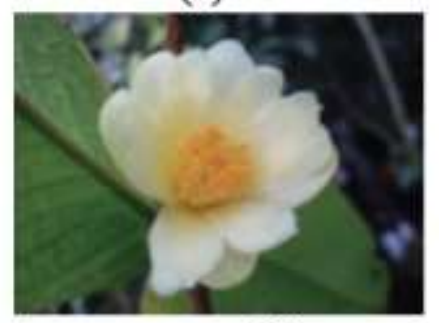

(h)
Natsu Tanikawa et al.2010

Fig. 5: Yellow flower Camellia species (a) C. chrysantha

(b) C. chrysantha (c) C. chrysantha var.

phaeopubisperma, (d) C. cucphuongensis, (e) C.

fusuiensis, (f) C. impressinervis, (g) C. ptilosperma, (h) C. quephongensis.

\subsection{Isolation, Stabilization and Characterization of} Xanthophyll from Marigold Flower- Tagetes Erecta-L. Marigold (Tagetes Erecta L), an ornamental plant belonging to the composite family, has a rich source of natural antioxidant-Lutein. A natural pigment, xanthophylls offer an alternative to synthetic dyes as a food colourant, due to its non-toxicity. Chromatographic separations of saponified and unsaponified oleoresin were performed and Trans-Lutein identified as the major constituent. Well-preserved flowers exhibit a high yield of Xanthophyll content $(105.19 \mathrm{~g} / \mathrm{Kg})$ in contrast to the unpreserved flower sample $(54.87 \mathrm{~g} / \mathrm{Kg})$, emphasizing the significance of flower preservation in the extraction of xanthophyll. The stability and amount of xanthophyll also increased from $105.19 \mathrm{~g} / \mathrm{Kg}$ to $226.88 \mathrm{~g} / \mathrm{Kg}$ on saponification and subsequent purification with Ethylene Dichloride (Pratheeshet al.2009).

Carotenoids are abundant in fruits and plants and are widely used an antioxidant and may be useful in the prevention of diseased including cancer. The consumption of lutein and zeaxanthin reduces $40 \%$ of the age related macular degeneration .The xanthophylls because of their yellow to orange-red colouration and natural occurrence in human foods, also finds its use as a food colourant. Therefore there exist a high demand for the significantly pure Xanthophyll that can be used as a food colourant and a nutrient supplement. Flowers such as Tagetes comprise different species about 33 in number, helenium, helianthus, sunflower, dandelion and many others. Of these, most concentrated source of xanthophylls is of the order $4500 \mathrm{mg} / \mathrm{lb}$ (Verghese, 1998b) in the petals of Tagetes Erecta L (African marigold, Aztec marigold, Zempasuchil). Marigold flower petals are a significant source of the Xanthophyll and have a much higher concentration of this pigment compared to other plant materials (Verghese, 1998a). Marigold flower (Tagetes Depending on the varieties, cultivar and horticulture practices, the yield of flower showed remarkable variations in number and in flower weight (from 11 to 30 ton/hectare). Although flower is made up of petals, calyx pedicle, seeds etc., approximately $40 \%$ to $50 \%$ of the flower consist of petals. Extraction studies of petals and total flower with hexane showed that only flower petals contain xanthophylls. Calyx contains chlorophyll which in-turn affects absorption of xanthophylls by broilers and layers (Verghese. J , 1998b). Hence, only the petals are used for the isolation of oleoresin. The main colouring component of Marigold flower is lutein (C40H56O2). Free Lutein hardly exists in the flower and it naturally occurs in the acylated form. The Lutein ester concentration in fresh Marigold flowers varies from 4 $\mathrm{mg} / \mathrm{Kg}$ in greenish yellow flowers to $800 \mathrm{mg} / \mathrm{Kg}$ in orange brown flowers (Sowbhagya et al. 2004). Darkcoloured flowers contain about 200 times more Lutein esters than the lightcoloured flowers. Xanthophyll content varies in the range of 9 to $11 \mathrm{~g} / \mathrm{Kg}$. The concentration of Lutein varies in different shades of marigold flowers, viz.; greenish yellow to bright yellow and orange brown (Gregoryet al.1986). Total Lutein esters have been reported to be in the range of 3.8 to $791 \mathrm{mg} / \mathrm{Kg}$ of flower (Sowbhagya et al. 2004). Lutein palmitate is the major ester in the flower. The other esters of lutein identified in 
the flower are dimyristate, myristate palmitate, palmitate sterate, and distearate. A purified extract of marigold petals mainly containing Xanthophylls dipalmitate is marketed as an ophthalmologic agent (Sowbhagya et al. 2004, Gau et al. 1983). Lutein is stable in pH range 3 to 9. At extreme $\mathrm{pH}$ and in the presence of light, lutein undergoes isomerization resulting in colour loss. Lutein structure consists of conjugated bonds, which when react with the oxygen present in air, cause oxidation to take place and lead to colour loss. Oxidation products of xanthophylls are mono and di-epoxides, carbonyls, alcohols etc. and extensive oxidation results in bleaching of carotenoid pigments. To minimize colour loss, it is safe to pack lutein-containing products in tin or opaque containers.
3.4. Biosynthesis of $\alpha$ - and $\beta$-ionone, prominent scent compounds, in flowers of Osmanthus fragrans.

Carotenoid derived volatiles are important fragrance compounds, which contribute to the scents of flowers from diverse taxa. A famous example is represented by the flowers of Osmanthus fragrans where apocarotenoids account for more than $20 \%$ of all volatiles (Fig.6). Biodegradation of carotenoids has been shown to be an important route for apocarotenoids formation. Here it has been reported on the contribution the $\mathrm{O}$. fragrans carotenoid cleavage dioxygenase 1 to the synthesis of the two predominant $\mathrm{C} 13$-apocarotenoids, $\alpha$ - and $\beta$-ionone, derived from $\alpha$-and $\beta$-carotene, respectively ,Susanne et al., 2012.

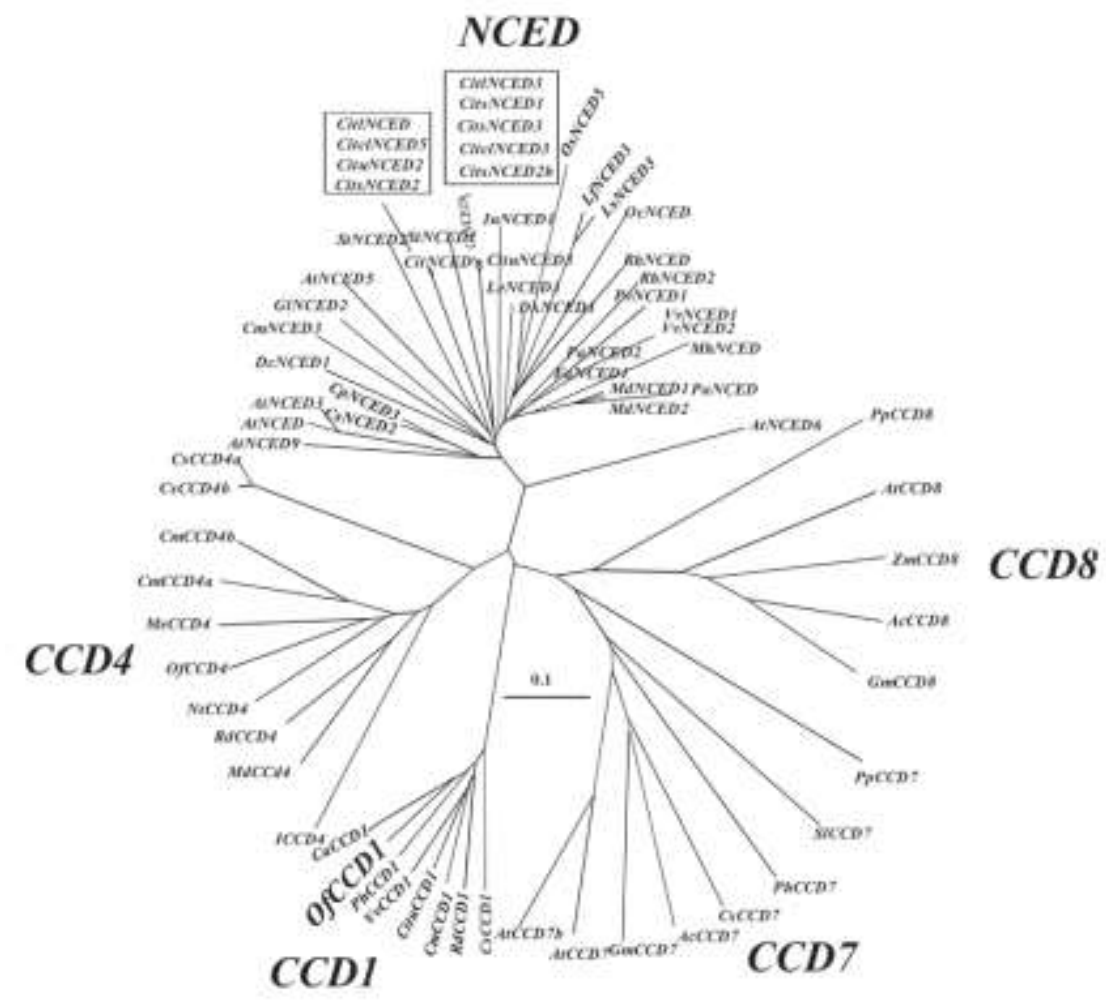

Susanne baldermann et al.2012

Fig.6: Unrooted phylogenetic tree of cDNA sequences of CCDs involved in the cleavage of carotenoids and apocarotenoids in Osmanthus fragrans

\subsection{Carotenoid Composition in the Yellow and Pale Green Petals of Primula Species.}

The carotenoid composition in the yellow petals of Primulaxpolyantha and P. helodoxa, and in the pale green petals of $P$. xpolyantha was analyzed by highperformance liquid chromatography(Fig. 7 a,b). The major carotenoids detected in the yellow petals were (9Z)violaxanthin, (all-E)-violaxanthin, lutein, and antheraxanthin. The carotenoid composition in the pale green petals was completely different from that in the yellow petals; the former accumulated predominantly lutein and $\beta$-carotene. Carotenoids in the yellow petals were present in the esterified form, while those in the pale green petals were in the free form (Chihiro Yamamizo et al.2011).

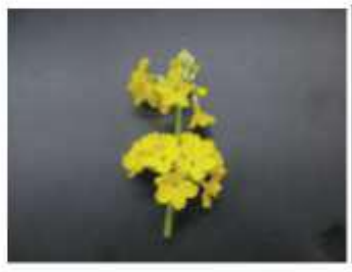

7a.P. ×polyantha (Yellow)

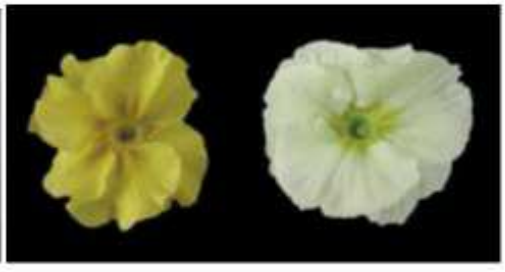

7b. P.× polyantha (Pale green)

Chihiro yamamizo et al.2011 


\section{REGULATION OF CAROTENOID BIOSYNTHESIS IN PETALS AND LEAVES OF CHRYSANTHEMUM (CHRYSANTHEMUM MORIFOLIUM)}

Carotenoid composition and the content and expression of genes encoding isoprenoid and carotenoid biosynthetic enzymes in petals and leaves of chrysanthemums were analyzed. Most of the carotenoids in yellow petals were $\beta$, $\varepsilon$-carotenoids, lutein and its derivatives, reflecting the high expression levels of lycopene $\varepsilon$-cyclase (LCYE). In contrast, the ratio of $\beta, \beta$-carotenoids to total carotenoids in leaves were higher than that of $\beta$, عcarotenoids, reflecting the high expression levels of lycopen $\beta$-cyclase (LCYB). Petals of the yellow-flowered cultivar Yellow Paragon showed increased accumulation and drastic componential changes of carotenoids as they mature. In petals of the white-flowered cultivar Paragon, carotenoid content was drastically decreased during petal development and became less than the detection limit late in development. Transcript levels of most genes tested increased during petal development in Yellow Paragon. All genes except that for 1-deoxyxylulose 5-phosphate synthase (DXS) showed similar expression patterns in Paragon. Between-cultivar comparison of the expression of these genes in the petals at mid-development showed no distinct differences between petal colour. It is possible that the formation of white petal colour is due to neither down-regulation nor destruction of the carotenoid biosynthetic pathway. We presume that another factor inhibits carotenoid accumulation in chrysanthemum petals.

The green tissues of most plants show similar carotenoid profiles, containing both $\beta, \varepsilon$-carotenoids ( $\alpha$-carotene derivatives) and $\beta, \beta$-carotenoids ( $\beta$-carotene derivatives) (Goodwin and Britton 1988). The essential carotenoids for plant photosynthesis, such as zeaxanthin, violaxanthin, and antheraxanthin, are invariably found in the green tissues. In contrast, carotenoids in flowers show distinctive compositions that depend on the plant species (Deli et al. 1988, Eugster and Märki-Fischer 1991, Kull and Pfander 1997, Maoka et al. 2000, Tai and Chen 2000, Kishimoto et al. 2005). For example, petals of tiger lily (Lilium lancifolium) contain only $\beta$-carotene derivatives (Deli et al. 2000). Compositae plants tend to accumulate mainly lutein, an $\alpha$-carotene derivative, and lutein derivatives in their petals; for example, marigold (Tagetes erecta) accumulate a large amount of lutein (Khachik et al. 1999).

In general, transcriptional activation of carotenoid biosynthetic enzymes is thought to be the major factor in the upregulation of carotenoid accumulation in many fruits and flowers (Hirschberg, 2001; Fraser and Bramley 2004; Taylor and Ramsay 2005). However, various other post-transcriptional factors coming into play during the regulatory process were reported recently (Al-Babili et al. 1996, Liu et al. 2004). A variety of factors might be involved in the regulation of carotenoid biosynthesis, therefore, further work in this area is required. It is well known that some plant species, especially horticultural crops, have a wide variety of carotenoid contents in petals even within the same species. Moehs et al. (2001) reported that DXS and PSY might be responsible for the colour development from pale yellow to deep yellow in marigold petals. In Sandersonia, petals of pale yellowflowered cultivars showed lower expression of PDS than those of yellow-flowered cultivars, and levels tended to be proportionate to carotenoid accumulation level (Nielsen et al. 2003).

Chrysanthemum (C. morifolium Ramat.) is one of the most important ornamental plants in the world, and the petal colour of yellow-flowered cultivars originates mainly from carotenoid pigments. Kishimoto etal. 2004 showed the uniqueness of the carotenoid composition in petals of chrysanthemum: approximately $92 \%$ of the total carotenoids isolated from petals of yellow-flowered chrysanthemum were lutein and its derivatives. This yellow colouration due to carotenoids in chrysanthemum petals is a recessive trait against a white one (Langton, 1980). Hattori (1991) suggested that a single dominant gene inhibiting carotenoid biosynthesis exists. The gene has not yet been identified, and the factor regulating carotenoid accumulation in chrysanthemum petals is still unknown.On analysis the carotenoid composition and content in petals and leaves of yellow- and white flowered chrysanthemum cultivars during their development showed the expression of genes encoding carotenoid and isoprenoid biosynthetic enzymes in those cultivars. By comparing the behaviour of carotenoid pigments and biosynthetic genes, clarified the factor that determines the characteristic accumulation of carotenoids in chrysanthemum petals.

\subsection{Materials and methods}

\subsubsection{Plant materials}

Three white-flowered cultivars (Paragon, White Marble, and Fiducia) and three yellow-flowered cultivars (Yellow Paragon, Florida Marble, and Sunny Orange) of chrysanthemum (Chrysanthemum morifolium Ramat.) were grown in greenhouses at the National Institute of Floricultural Science (Tsukuba, Ibaraki, Japan) (Fig.8 B). Yellow Paragon and Florida Marble are bud variants of Paragon and White Marble, respectively. Petal development was divided into four stages from which RNAs and carotenoids were extracted: very early (VE), early (E), middle (M), and late (L) (Fig.8 A). The lengths of petals were ca. 2-3 $\mathrm{mm}$ at stage VE, ca. $8-10 \mathrm{~mm}$ at stage E, ca. $15-18$ $\mathrm{mm}$ at stage $\mathrm{M}$, and ca. $30-35 \mathrm{~mm}$ at stage L. Flowers 
were fully opened at stage L. Leaf development was divided into three stages from which carotenoids were extracted: early (E), middle (M), and late (L). RNAs were extracted from stage L. The lengths of leaves were ca. $15-25 \mathrm{~mm}$ at stage E, ca. $35-45 \mathrm{~mm}$ at stage $\mathrm{M}$, and ca. $60-70 \mathrm{~mm}$ at stage L. Leaves were fully developed at stage $\mathrm{L}$.
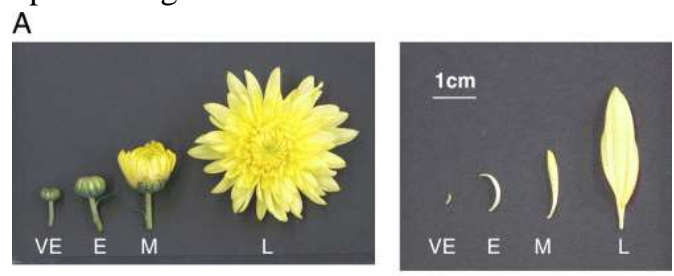

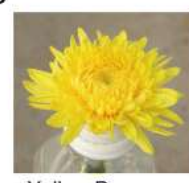

Yellow Paragon

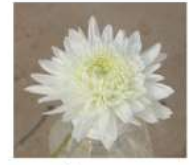

Paragon

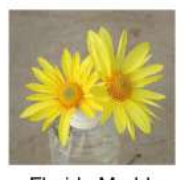

Florida Marble

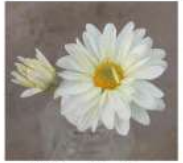

White Marble

Kishimoto and Ohmiya et al.2006

Fig.8. (A) Sampling stages of chrysanthemum petal development and $(B)$ fully expanded flowers of chrysanthemum cultivars used for the experiment. $V E=$ very early, $E=$ early, $M=$ medium, and $L=$ late.

\subsubsection{Carotenoid extraction and HPLC analysis.}

Each extract was analysed by HPLC with a Jasco MD915 photodiode array detector (Jasco, Tokyo, Japan). HPLC analysis was performed under the following conditions: column, YMC Carotenoid $(250 \times 4.6 \mathrm{~mm}$ i.d., $5 \mu \mathrm{m}$; YMC, Kyoto, Japan); solvent A, methanol $(\mathrm{MeOH}) /$ methyl tert-butyl ether (MTBE) / $\mathrm{H} 2 \mathrm{O}=$ 90:6:4 (v/v/v); solvent B, MeOH / MTBE / H2O = 25:71:4; gradient, 0/100, 12/100, 96/0 ( $\mathrm{min} / \% \mathrm{~A})$; flow rate, $1.0 \mathrm{~mL} \mathrm{min-1;} \mathrm{column} \mathrm{temperature,} 35{ }^{\circ} \mathrm{C}$; UV/visible monitoring range, 200-600 $\mathrm{nm}$. The amounts of total carotenoids were calculated according to the total peak area of HPLC chromatograms at a wavelength of $450 \mathrm{~nm}$.

\subsubsection{HPLC analysis of carotenoids:}

The carotenoid components and concentrations at the four stages of petal development in Yellow Paragon and Paragon are shown in Figures 9 and 10, respectively. Petals of Yellow Paragon showed increased accumulation and drastic componential changes of carotenoids as they matured. Lutein, $\beta$ carotene, and violaxanthin were detected at stage VE, then violaxanthin and $\beta$-carotene disappeared and lutein was dominant at stage E. At stage $\mathrm{M},(3 S, 5 \mathrm{~S}$, $\left.6 \mathrm{R}, 3^{\prime} R, 6^{\prime} R\right)-5$, 6-dihydro-5, 6-dihydroxylutein, cisforms of lutein $\left((9 Z)\right.$-lutein and $\left(9^{\prime} Z\right)$-lutein), and lutein epoxides ((9Z)-lutein-5, 6-epoxide and (9'Z)-lutein-5, 6 -epoxide) were detected in addition to lutein. The chromatogram at stage $\mathrm{L}$ showed a large decrease in lutein and $\left(9^{\prime} Z\right)$-lutein contents, and a drastic increase in $(9 Z)$ - lutein and $\left(9^{\prime} Z\right)$-lutein-5, 6-epoxide contents. 

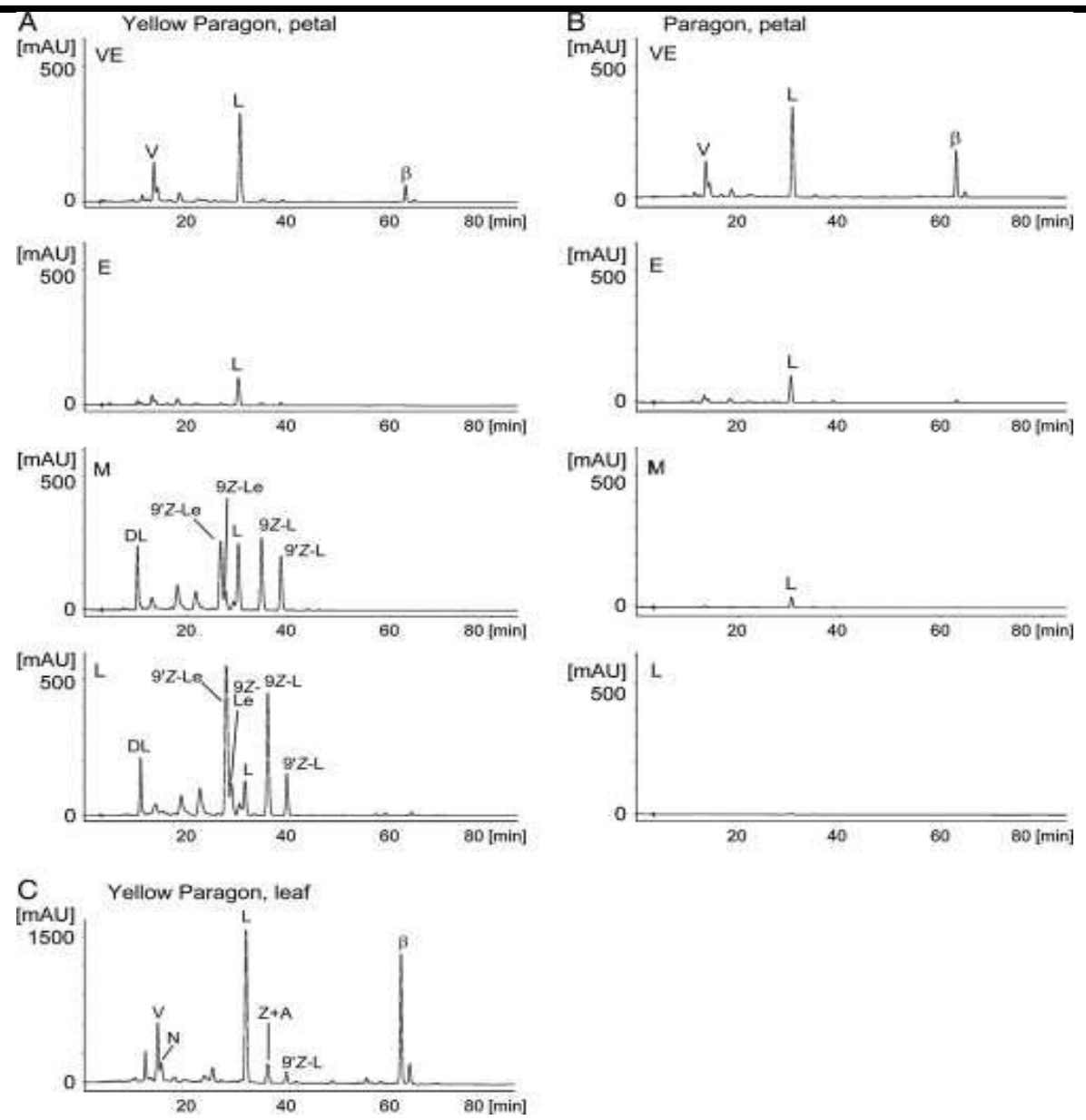

Kishimoto and Ohmiya et al.2006

Fig. 9: Carotenoid analysis in petals and leaves of Yellow Paragon and Paragon. Carotenoid extracts from $0.1 \mathrm{~g}$ f.w. of petals of (A) Yellow Paragon and (B) Paragon, and (C) leaves of Yellow Paragon were analysed by HPLC.

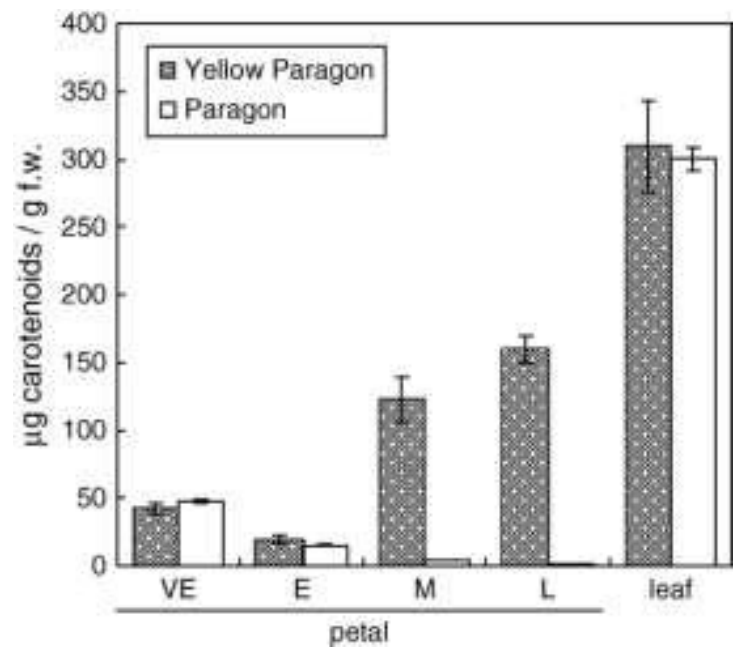

Kishimoto and Ohmiya et al.2006

Fig.10: Total carotenoid contents in petals and leaves of Yellow Paragon and Paragon.

\subsubsection{Comparison of gene expression between petals and leaves.}

In the comparison of petals and leaves by Northern analysis, the most striking feature was the difference in expression levels of LCYB and LCYE. Real-time PCR was performed to compare the expression levels of these genes. In petals of yellow-flowered cultivars, the levels of
LCYE transcripts were remarkably higher than those of LCYB. In contrast, LCYE showed extremely lower levels in leaves, reflecting the lower ratio of $\beta, \varepsilon$-carotenoid content. Leaves showed higher transcription levels of ZEP and VDE, which encode enzymes that catalyse the synthesis of carotenoids that are essential for photosynthesis, than did petals . The expression level of 
DXR was also remarkably higher in leaves. On the other hand, levels of DXS and CHYB were lower in leaves.

\subsubsection{Carotenoid Cleavage Dioxygenase (CmCCD4a) Contributes to White Colour Formation in Chrysanthemum Petals.}

The white petals of chrysanthemum (Chrysanthemum morifolium Ramat.) are believed to contain a factor that inhibits the accumulation of carotenoids. To find this factor, polymerase chain reaction- Select subtraction screening was performed and obtained a clone expressed differentially in white and yellow petals. The deduced amino acid sequence of the protein (designated CmCCD4a) encoded by the clone was highly homologous to the sequence of carotenoid cleavage dioxygenase. All the white-flowered chrysanthemum cultivars tested showed high levels of $\mathrm{CmCCD} 4 a$ transcript in their petals, whereas most of the yellow flowered cultivars showed extremely low levels. Expression of $\mathrm{CmCCD} 4 \mathrm{a}$ was strictly limited to flower petals and was not detected in other organs, such as the root, stem, or leaf. White petals turned yellow after the RNAi construct of $\mathrm{CmCCD} 4 \mathrm{a}$ was introduced. These results indicate that in white petals of chrysanthemums, carotenoids are synthesized but are subsequently degraded into colourless compounds, which results in the white colour. The chrysanthemum (Chrysanthemum morifolium Ramat.), which has been bred for more than 2,000 years, is one of the most important ornamental flowers in the world. The petal colour of yellow-flowered cultivars originates mainly from carotenoids. Understanding the mechanism that controls carotenoid accumulation in petals will not only contribute greatly to the breeding of chrysanthemums and other flowering plants but also provide important information about the molecular evolutionary mechanisms responsible for different petal colours. Cultivated chrysanthemums are thought to have originated from hybrids between white- and yellowflowered wild species. On the basis of an experiment in which white- and yellow-flowered chrysanthemums were crossed, Hattori (1991) observed that the white petal colour is dominant over yellow and suggested that a single dominant gene that inhibits carotenoid accumulation may exist. The detailed function of such a gene, however, is still unknown. Kishimoto and Ohmiya (2006) demonstrated no significant difference between the expression levels of carotenoid biosynthetic genes in white and yellow petals during the course of development. In addition, the carotenoid content in immature white petals is almost equal to that in yellow petals, and the carotenoid content decreases to undetectable levels as the white petals mature. These results indicate that the formation of white colour is caused neither by down regulation nor by disruption of the carotenoid biosynthetic pathway.To find a factor that controls carotenoid content in chrysanthemum petals, PCR-Select subtraction screening was performed to search for cDNAs that were differentially expressed in white and yellow petals.

\subsubsection{Suppression of $\mathrm{CmCCD} 4 a$ Expression by RNAi.}

To determine the role of $C m C C D 4 a$ gene products in the formation of petal colour, transgenic chrysanthemum plants were produced with reduced expression of CmCCD4a. The RNAi construct of CmCCD4a was introduced under the control of the tobacco (Nicotiana tabacum) elongation factor $1 \alpha$ promoter into the whiteflowered chrysanthemum cultivar Sei-Marine. Five independently derived transgenic plants were analysed. Carotenoid content values in middle-stage petals of these transgenic lines were about 3 to 6 times the values observed in wild-type plants (Fig.11 A). During late-stage petal development, when petals of wild-type plants completely lost their carotenoids, the petals of transgenic lines contained 3 to $8 \mu \mathrm{g} / \mathrm{g}$ fresh weight of carotenoids and looked yellow (Fig. 11 B). Quantitative real-time RTPCR analysis showed that the petals of the transgenic lines expressed the $\mathrm{CmCCD} 4 \mathrm{a}$ gene at only $2 \%$ to $4 \%$ of the wild-type level.

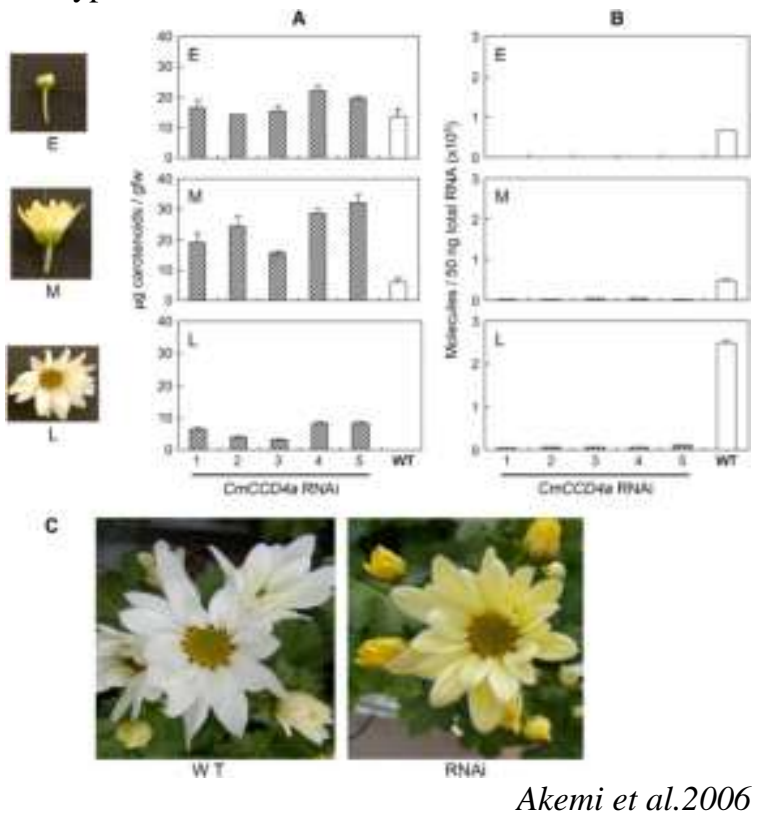

Fig.11: Suppression of CmCCD4a expression by RNAi. A,

Changes in carotenoid concentrations during petal development of wild-type (WT) and five independent CmCCD4a RNAi plants (1-5).

\subsubsection{CmCCD4a in Wild Chrysanthemum Species} Genomic PCR analysis was also performed in whiteand yellow-flowered wild species of chrysanthemum (Fig.12). The bands that corresponded to $\mathrm{CmCCD} 4 \mathrm{a}$ were observed in all the white-flowered species but not in the yellow-flowered species. In contrast, the bands that corresponded to $C m C C D 4 b$ were observed in both white- and yellow-flowered species. 


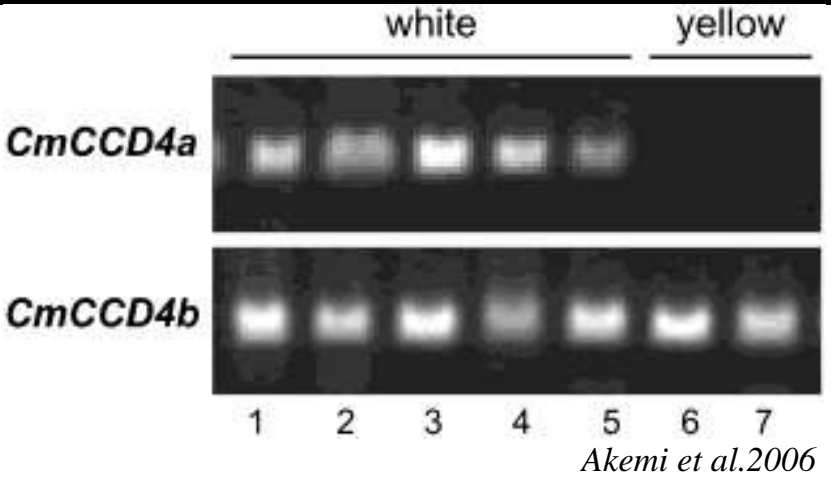

Fig.12: Genomic PCR of white- and yellow-flowered wild species of chrysanthemum with CmCCD4a and

CmCCD4b primers: 1, Chrysanthemum boreale; 2 , Chrysanthemum indicum; 3, Chrysanthemum makinoi; 4, Chrysanthemum japonese; 5, Chrysanthemum yezoense; 6, Chrysanthemum sp.

\subsubsection{Light Microscope Observation of Transverse Sections of Petals.}

Among yellow-flowered cultivars, only Yellow Paragon expressed $\mathrm{CmCCD} 4 \mathrm{a}$ in petals. It is possible that petals of Yellow Paragon are periclinal chimera, and either the L1 or the L2 layer may behave genetically in a manner identical to that of the white progenitor Paragon. Periclinal structures were determined by microscope examination of transverse sections of petals (Fig.13). In the sections of Yellow Paragon, yellow pigmentation was localized in the adaxial epidermis (L1 layer), and the underlying mesophyll (L2 layer) appeared to be white. In contrast, both the L1 and L2 layers were yellow in petals of Super Yellow.
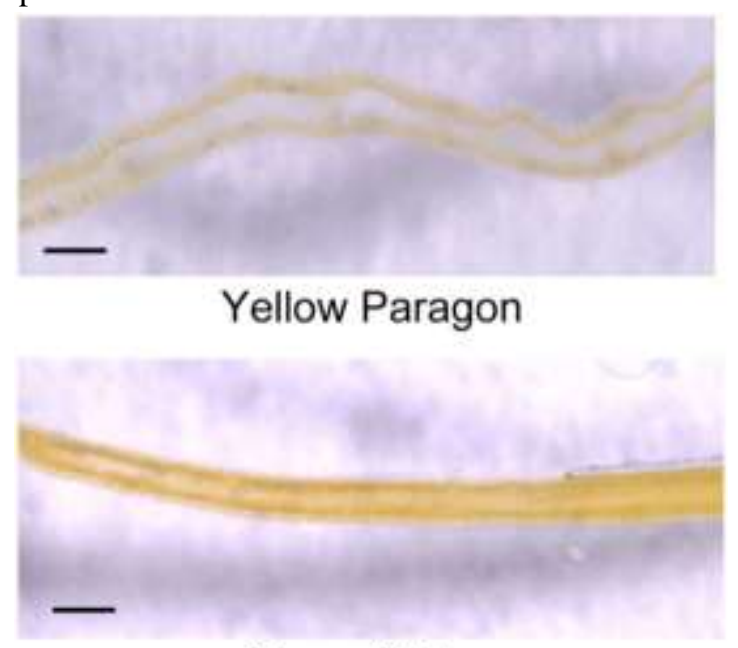

\section{Super Yellow}

Akemi et al.2006

Fig. 13: Light microscope observation of transverse section through petals of Yellow-flowered cultivars Yellow Paragon and Super Yellow.

\section{CONCLUSION}

- Knowledge at the biochemical and molecular level has made it possible to develop novel colour which are otherwise absent in nature.

- Metabolic cross-stock between different pathway makes the production of transgenic challenging.

- Petals of the yellow-flowered cultivar Yellow Paragon showed increased accumulation and drastic componential changes of carotenoids as they mature, compared to petals of the white-flowered cultivar Paragon that showed drastically decreased carotenoid content during petal development.

- All the white-flowered chrysanthemum cultivars tested showed high levels of CmCCD4a transcript in their petals, whereas most of the yellow flowered cultivars showed extremely low levels indicating that in white petals of chrysanthemums, carotenoids are synthesized but subsequently degraded into colourless compounds, which results in the white colour.

- Studying the regulatory mechanisms underlying carotenoid accumulation in Ipomoea plants at the molecular level will help in producing yellowflowered cultivars by plant transformation.

\section{REFERENCES}

[1] Akemi Ohmiya, Sanae Kishimoto, Ryutaro Aida, SatoshiYoshioka, and Katsuhiko Sumitomo.2006. Carotenoid Cleavage Dioxygenase (CmCCD4a) Contributes to White Color Formation in Chrysanthemum Petals. Plant Physiology. 142(3): 1193-1201.

[2] Al-Babili S, Von Lintig J, Haubruck H, Beyer P (1996) .A novel, soluble form of phytoene desaturase from Narcissus pseudonarcissus chromoplasts is Hsp70-complexed and competent for flavinylation, membrane association and enzymatic activation. Plant J.9: 601-612.

[3] Beisel, K.G., Jahnke, S., Hofmann, D., Köppchen, S., Schurr, U. et al. (2010). Continuous turnover of carotenes and chlorophyll $a$ in mature leaves of Arabidopsis revealed by $14 \mathrm{CO} 2$ pulse-chase labelling. Plant Physiology.152:2188-2199.

[4] Britton, G (1998). Overview of carotenoid biosynthesis. In:Britton G,Liaaen-Jensen $\mathrm{S}$, PfanderH (eds) Carotenoids, Vol. 3. Birkhäuser, Basel, pp 13-147.

[5] Cazzonelli, C.I. and Pogson, B.J (2010). Source to sink: Regulation of carotenoid biosynthesis in plants. Trends Plant Science. 15: 266-274.

[6] Chihiro Yamamizo, Sanae Kishimoto, and Akemi Ohmiya (2010).Carotenoid composition and carotenogenic gene expression during Ipomoea petal 
development. Journal of Experimental Botany. 61(3): 709-719.

[7] Chihiro YAMAMIZO, Masumi HIRASHIMA, Sanae KISHIMOTO and Akemi OHMIYA (2011). Carotenoid Composition in the Yellow and Pale Green Petals of Primula Species. Bull.Natl. Inst. Flor. Sci. 11:67-72.

[8] Cunningham, F.X. and Gantt, E. (1998). Genes and enzymes of carotenoid biosynthesis in plants. Annual Review Plant Physiology. Plant Molecular Biology. 49: 557-583.

[9] Cunningham, F. and Gantt, E (2001).One ring or two? Determination of ring number in carotenoids by lycopene $\varepsilon$-cyclases. Proc. Natl. Academy Science USA. 98:2905-2910.

[10] Deli J, Molnár P, Pfander H, Tóth G (2000). Isolation of capsanthin 5, 6-epoxide from Lilium tigrinum. Acta Bot Hung. 42: 105-110.

[11]Deli J, Molnár P, Tóth G, Szabolcs J, Radics L (1988). Determination of the geometrical Configuration of naturally occurring mono-cis-lutein epoxides. Phytochemistry .27:547-549.

[12] Demmig-Adams, B. and Adams, W.W (2002). Antioxidants in photosynthesis and human nutrition. Science. 298: 2149-2153.

[13] Eugster CH, Märki-Fischer E (1991). The chemistry of rose pigments. Angew Chem, Inted Eng. 30: 654672.

[14] Fraser P.D, Bramley P.M (2004). The biosynthesis and nutritional uses of carotenoids. Prog. Lipid Res. 43: 228-265.

[15] Gau, W., Plosche, H. J., Wunsche, C. (1983). Mass spectrometric identification of xanthophyll fatty acid esters from Marigold flowers (Tagetes Erecta) obtained by high performance liquid chromatography and counter current distribution. Journal of Chromatography. 262: 277-284.

[16] Goodwin TW, Britton G (1988). Distribution and analysis of carotenoids.In: Goodwin TW (ed) Plant Pigments. Academic Press, London, 62-132.

[17] Gregory, G.K.; Chen, T.S.; Philip, T. (1986). Quantitative analysis of lutein esters in marigold flowers by high performance liquid chromatography. Journal of Food Science.51: 1093-1094.

[18] Grotewold E (2006).The genetics and biochemistry of floral pigments. Annual Review of Plant Biology.57:761-780.

[19] Giuliano, G., Tavazza, R., Diretto, G., Beyer, P. and Taylor, M.A (2008). Metabolic engineering of carotenoid biosynthesis in plants. Trends Biotechnology. 26: 139-145.

[20] Hattori, K (1991). Inheritance of carotenoid pigmentation in flower colour of chrysanthemum. Jpn J Breed.41: 1-9.
[21] Hirschberg, J (2001). Carotenoid biosynthesis in flowering plants. Curr Opin Plant Biol.4: 210-218.

[22] Howitt, C.A. and Pogson, B.J (2006). Carotenoid accumulation and function in seeds and non-green tissues. Plant Cell Environ. 29:435-445.

[23] Khachik F, Steck A, Pfander H (1999). Isolation and structural elucidation of $\left(13 \mathrm{Z}, 13^{\prime} \mathrm{Z}, 3 \mathrm{R}, 3^{\prime} \mathrm{R}\right.$, $6^{\prime} \mathrm{R}$ )-lutein from marigold flowers, kale, and human plasma. J Agric Food Chem .47: 455-461

[24] Kishimoto S, Maoka T, Nakayama M, Ohmiya A (2004). Carotenoid composition in petals of chrysanthemum (Dendranthema grandiflorum (Ramat.) Kitamura). Phytochemistry .65:2781-2787.

[25] Kishimoto S, Maoka T, Sumitomo K, Ohmiya A (2005) .Analysis of carotenoid composition in petals of calendula (Calendula officinalis L.). Biosci Biotech Biochem .69: 2122-2128.

[26] Kishimoto, S. and Ohmiya, A (2006). Regulation of carotenoid biosynthesis in petals and leaves of chrysanthemum (Chrysanthemum morifolium). Physiologia Plantarum. 128: 436-447.

[27] Kull D, Pfander H (1997). Isolation and structure elucidation of two (Z)-isomers of lutein from the petals of rape (Brassica napus). J Agric Food Chem. 45: 4201-4203

[28] Langton, F.A (1980). Chimerical structure and carotenoid inheritance in Chrysanthemum Morifolium (Ramat.). Euphytica .29: 807-812.

[29] Liu Y, Roof S, Ye Z, Barry C, Van Tuinen A, Vrebalov J, Bowler C, Giovannoni J (2004).Manipulation of light signal transduction as a means of modifying fruit nutritional quality in tomato. Proc Natl Acad Sci USA. 101: 9897-9902.

[30] Maoka T, Fujiwara Y, Hashimoto K, Takeda S, Takaragaki S, Ida K (2000). A new retrocarotenoid from the petals of the Californian yellow poppy Eschscholzia californica. J Nat Prod .63: 12881289.

[31] Moehs CP, Tian L, Osteryoung KW, Della Penna D (2001). Analysis of carotenoid biosynthetic gene expression during marigold petal development. Plant Mol Biol .45: 281-293.

[32] Natsu TANIKAWA, Chihiro YAMAMIZO and Akemi OHMIYA (2010). Carotenoid Components in Petals of Yellow Flower Camellia Species.Bull. Natl. Inst. Flor. Sci. 10:7579.

[33] Nielsen KM, Lewis DH, Morgan ER (2003) Characterization of carotenoid pigments and their biosynthesis in two yellow flowered lines of Sandersonia aurantiaca (Hook.). Euphytica 130: 2534.

[34] Paolillo, D.J., Garvin, D.F. and Parthasarathy, M.V (2004). The chromoplasts of $\mathrm{Or}$ mutants of 
cauliflower (Brassica oleracea l. Var. Botrytis). Protoplasma, 224: 245-253.

[35] Sowbhagya. H. B, S. R. Sampathu, Krishnamurthy. (2004). Natural Colourant from Marigold-Chemistry and Technology Food reviews International. 20(1): 33-50.

[36] Susanne Baldermann, Masaya Kato, Peter Fleischmann and Naoharu Watanabe. (2012).Biosynthesis of $\alpha$ - and $\beta$-ionone, prominent scent compounds, in Flowers ofOsmanthus fragrans.Acta biochemica polonica.59: 79-81.

[37] Tai C-Y, Chen BH (2000). Analysis and stability of carotenoids in the flowers of daylily (Hemerocallis disticha) as affected by various treatments. J Agric Food Chem. 48:5962-5968.

[38] Tanaka, Y. and Ohmiya, A. (2008) Seeing is believing: Engineering anthocyanin and carotenoid biosynthetic pathways. Curr. Opin.Biotechnology.19(2):190-197

[39] Taylor M, Ramsay G. (2005). Carotenoid biosynthesis in plant storage organs: recent advances and prospects for improving plant food quality. Physiol Plant .124: 143-151.

[40] Toledo-Ortiz, G.; Huq, E. \& Rodrígurz-Concepción, M. (2010). Direct regulation of Phytoene synthase gene expression and carotenoid biosynthesis by Phytochrome-Interacting Factors. 107(25): 1162611631.

[41] V.B. Pratheesh, Nify Benny \& C.H Sujatha (2009). Isolation, Stabilization and Characterization of Xanthophyll from Marigold Flower- Tagetes ErectaL.ccsenet/journal.html.

[42] Verghese, J (1998a). Focus on xanthophylls from Tagetes Erecta $\mathrm{L}$ the giant natural complex-I. Indian Spices. 33(4):8-13.

[43] Verghese, J. (1998b). Focus on xanthophylls from Tagetes Erecta L the giant natural colour complex-II. Indian Spices .34(1\&2): 13-16.

[44] Vogel, J.T., Walter, M.H., Giavalisco, P., Lytovchenko, A., Kohlen, W., et al. (2010).Slccd7 controls strigolactone biosynthesis, shoot branching and mycorrhiza-induced apocarotenoid formation in tomato. Plant Journal. 61: 300-311.

[45] Walter, M.H. and Strack, D (2011). Carotenoids and their cleavage products: Biosynthesis and functions.Natural Production Report.28: 663-692. 